\title{
PARTICULARIDADES ACERCA DE LA AUTORIDAD JUDICIAL COMPETENTE EN SUPUESTOS DE SUSTRACCIÓN ILÍCITA DE MENORES EN ARAS DEL REGLAMENTO (CE) 2201/ 2003
}

\author{
PECULIARITIES ABOUT JUDICIAL AUTHORITY IN CASE \\ OF INTERNATIONAL CHILD ABDUCTION FOR THE PURPOSE \\ OF COUNCIL REGULATION (EC) 2201/2003
}

\author{
David CARRIzo Aguado \\ Profesor Ayudante Doctor de Derecho internacional privado \\ Universidad de León \\ ORCID ID: 0000-0002-9427-287X
}

Recibido: 06.04.2020 / Aceptado: 04.05.2020

DOI: https://doi.org/10.20318/cdt.2020.5611

\begin{abstract}
Resumen: La mayor parte del conjunto de casos de sustracción internacional de menores son una manifestación trágica y dolorosa de una crisis matrimonial o de pareja. En este marco de actuación, la retención transfronteriza, frente a las situaciones estrictamente internas, posee como elemento distintivo el desplazamiento o traslado del menor a cargo del sustractor con el fin de encontrar un sistema legal de cobertura distinto y más favorable a sus intereses. Para evitar múltiples perjuicios y, con miras a preservar el interés superior del menor, el Reglamento (CE) 2201/2003 blinda la competencia en esta materia a favor de los tribunales de la residencia habitual del menor. Si bien, la gran diversidad de causas que subyacen en el secuestro de menores no deben ser ignoradas a la hora de proponer la solución más adecuada.

Palabras clave: Litigación transnacional, secuestro internacional de menores, residencia habitual, interés superior del menor.
\end{abstract}

Abstract: Most of the set of international child abduction cases are a tragic and painful manifestation of a marriage or couple crisis. In this framework, cross-border withholding, in the face of strictly internal situations, has as its distinctive element the displacement or transfer of the minor in charge of the abducer in order to find a different legal system of coverage that is more favorable to his interests. To avoid multiple damages and in order to preserve the best interests of the minor, Council Regulation (EC) 2201/2003 shields competition in this matter in favor of the courts of the minor's habitual residence. Although, the great diversity of causes underlying child abduction should not be ignored when proposing the most appropriate solution.

Keywords: Transnational litigation, international child abduction, habitual residence, the best interest of the child.

Sumario: I. Cuestiones introductorias. 1.1. Contextualización. 1.2. Caracteres esenciales: desplazamiento transfronterizo ilícito. II. Marco regulatorio. III. Retrospección del foro de la resi-

${ }^{*}$ Este trabajo se ha realizado en el marco del proyecto de investigación emergente $\mathrm{I}+\mathrm{D}+\mathrm{i}$ financiado por la Generalitat Valenciana (con referencia GV/2019/118) titulado "La tutela de los derechos en el entorno digital: nuevos retos, desafíos y oportunidades", Investigador Principal José Juan Castelló Pastor del que el autor es miembro del grupo de investigación. 
dencia habitual del menor establecido por el Reglamento (CE) 2201/2003. 1. Observación inicial. 2. Perspectiva jurisprudencial -europea y española- con comunicación bidireccional. 3. Límite de maniobra para el juez: acatamiento del principio «favor minoris». IV. Últimas líneas reflexivas.

\section{Cuestiones introductorias}

\section{Contextualización}

1. El auge de la globalización ha incrementado el número de asuntos en la jurisdicción de familia en los que existe al menos un elemento internacional ${ }^{1}$. De este modo, la creciente movilidad de los ciudadanos dentro de la Unión Europea ha comportado un aumento considerable de familias con dimensión transnacional ${ }^{2}$, en particular, aquellas cuyos miembros presentan diferente nacionalidad o residen en Estados diferentes ${ }^{3}$.

2. En los litigios con elemento extranjero debe tenerse en cuenta que, cada medida controvertida puede estar sometida a la aplicación en materia competencial de distintos instrumentos internacionales, lo que puede provocar dispersión jurisdiccional del pleito con la consecuencia negativa de multiplicación no solo de las normas aplicables, sino incluso, de los tribunales estatales competentes, pudiendo obligar a los particulares a tener que litigar en países distintos en función de la tutela judicial que se pretenda ${ }^{4}$.

Es más, cada vez el protagonismo de las fuentes de producción institucional es mayor, lo que no obedece al clásico principio de jerarquía normativa sino a la coherencia del sistema jurídico que ha optado por dar un paso más hacia el sistema de la integración jurídica, en ámbitos caracterizados por la globalización en la conformación de las relaciones jurídicas. De esta suerte, en el marco de cesión de la soberanía a favor de las instituciones europeas, se están dando pasos muy importantes en la línea de la potenciación de las libertades comunitarias que principalmente en este ámbito, serían la libre circulación de personas, resoluciones judiciales y el respeto de los derechos fundamentales ${ }^{5}$.

\footnotetext{
${ }^{1}$ Comienza a constatarse que las relaciones familiares experimentan una creciente internacionalización puesto que la libre circulación de personas conlleva, junto a la dimensión económica, derechos personales; en la sociedad globalizada en la que vivimos son muchos los problemas que afectan a menores (Vid. $\mathrm{M}^{\mathrm{a}}$.A. RodríGuEZ VÁzQuEz, "Los avances de la normativa comunitaria en materia de protección de menores" en M. Di Filippo / B. Campuzano Díaz / A. Rodríguez Benot / Má.A. Rodríguez VÁzQUEZ (coords.), Hacia un derecho conflictual europeo: realizaciones y perspectivas. Verso un diritto internazionale privato europeo: risultati e prospettive, Universidad de Sevilla, 2008, pp. 151-152). La inmigración de personas procedentes de países con leyes y costumbres muy distintas a las nuestras y, la evolución del concepto de familia en las democracias occidentales ha conllevado la adecuación del Derecho internacional privado de la familia planteándose, por tanto, nuevos retos (vid. N. BouZA I VIDAL, "Los problemas que plantea el Derecho de familia y sucesiones en el Derecho internacional privado" en AA.VV., Revista La Notaria, 150 anys, 1858-2008, Editorial Bosch y Colegi Notarial de Catalunya, Barcelona, 2008, pp. 1224 y ss.).

2 El Derecho de familia se ha visto afectado en las últimas décadas por los movimientos migratorios y la internacionalización de las relaciones privadas de las personas cuyas vidas se conectan con más de un país. Muchas dificultades se plantean, tales como el tratamiento de instituciones jurídicas extranjeras, la determinación de la ley aplicable al caso concreto o el reconocimiento del estado civil de unos países a otros (Vid. C. AzcÁrraga Monzonís, "Relaciones familiares internacionales. Nuevos retos en un mundo globalizado", El Foro, n 15, 2014, pp. 99-116).

${ }^{3}$ En este contexto, como pieza clave, condicionante y habilitante de la movilidad de las personas, se encuentra el derecho a la vida familiar que requiere conciliarse con el ejercicio del derecho a circular y a residir en otro Estado. La movilidad transfronteriza de personas requiere una adecuada protección de su derecho a la vida familiar, lo que implica, en consecuencia, la posibilidad de trasladarse y residir con los miembros de la familia en otro Estado (Vid. P. JimÉNEz BlAnCo, "Movilidad transfronteriza de personas, vida familiar y Derecho internacional privado", Revista electrónica de estudios internacionales (REEI), no 35, 2018; M. REQUEJO ISIDRo, "El derecho al respeto a la vida privada y familiar y el secuestro internacional de menores. Los Estados miembros de la UE ante el TEDH: estado de la cuestión", en J. Soroeta Liceras, Anuario de los cursos de derechos humanos de Donostia-San Sebastián, vol. XVI, 2017, pp. 283-320).

${ }^{4}$ E. Santana PÉrez, "Experiencias de los tribunales en materia de responsabilidad parental y retención ilícita de menores: algunos retos y cuestiones controvertidas" en C. Otero García-CAStrillón (dir.), Justicia civil en la Unión Europea. Evaluación de la experiencia española y perspectivas de futuro, Dykinson, Madrid, 2017, p. 233.

${ }^{5}$ C. Honorati, "Sottrazione internazionale dei minori e diritti fondamentali", Rivista di diritto internazionale privato e processuale, vol. 49, n 1, 2013, pp. 5-42; M. Guzmán PeCes, "La competencia judicial en materia de nulidad, separación y
} 
3. Evidentemente, los casos de sustracción internacional de menores son un problema social creciente que no se detiene ${ }^{6} \mathrm{y}$, que en múltiples ocasiones, está marcado por el conflicto de civilizaciones. Las peculiares estructuras familiares de sociedades lejanas a las occidentales, como las islámicas, hacen que con frecuencia los tribunales favorezcan en materia de custodia del niño, al padre o madre nacional, propiciando que el progenitor extranjero desplace ilícitamente al menor a su país de origen ${ }^{7}$.

A las tradicionales parejas mixtas entre personas de distinta nacionalidad, se suman hoy aquellas en las que sus integrantes residen en países distintos, la necesidad de desplazarse de un país a otro y, el cambio frecuente de centro de intereses personales, al margen de que vaya unido o no a un traslado del menor ${ }^{8}$.

4. En este contexto, la concurrencia del elemento transnacional genera el supuesto más grave, pues las dificultades para restablecer el statu quo anterior son mucho mayores, entre otras cosas porque quien así actúa es normalmente ciudadano del país de refugio y, lo que pretende con su actuación, es crear un fuero artificial para que la contienda sobre la custodia se resuelva conforme a sus intereses. Esta búsqueda de unos tribunales $a d h o c$, favorecedores de las posiciones de los secuestradores, es especialmente dramática en supuestos en los que los progenitores son, no solo de distintas nacionalidades, sino pertenecientes a distintas culturas o civilizaciones9.

\section{Caracteres esenciales: desplazamiento transfronterizo ilícito}

5. Podemos definir el fenómeno de retención transaccional ilícita de un menor como aquella situación en la que uno de los progenitores -el sustractor- sin el consentimiento del otro progenitor -aquel privado del menor- traslada o retiene a su hijo menor de edad desde el Estado donde este reside habitualmente a otro Estado diferente de manera ilícita, esto es, sin estar autorizado para hacerlo ${ }^{10}$. Se precisa que exista un efectivo desplazamiento internaciona ${ }^{11}$ que aparte al menor del otro progenitor $y$, que dicho desplazamiento sea la causa de un efectivo cambio o variación sustancial del status del niño. ${ }^{12}$

divorcio; responsabilidad parental y sustracción civil de menores en Derecho internacional privado español" en M. GuZMÁN Zapater / M. Herranz Ballesteros (dirs.), Crisis matrimoniales internacionales y sus efectos derecho español y de la Unión Europea. Estudio normativo y jurisprudencial, Tirant lo Blanch, Valencia, 2018, pp. 243-244; M. WiLderspin, "Derechos fundamentales en materia de derecho de familia: en particular, la sustracción de menores", Anuario Español de Derecho Internacional Privado, $\mathrm{n}^{\mathrm{o}} 11,2011$, pp. 527-558.

${ }^{6}$ La libre circulación es una premisa que no se puede obviar, y, no se puede ejercer un control férreo sobre esta cuestión. Lo que sí se puede hacer es garantizar la inmediata restitución del menor al país de su residencia habitual, vid. en este sentido, I. LoRENTE MARTínez, "La integración europea en el Derecho de Familia. Sustracción internacional de Menores: el caso Juana Rivas”, Ars Iuris Salmanticensis: AIS: revista europea e iberoamericana de pensamiento y análisis de derecho, ciencia política y criminología, vol. 7, nº 2, 2019, p. 201.

${ }^{7}$ Si bien, no se puede señalarse como una única causa de este complejo problema, sino que la concatenación de diferentes factores es la que ha propiciado que el número de secuestros internacionales sea muy elevado (Cfr. M.P. Diago Diago, "Secuestro internacional de menores: marco jurídico", Aequalitas: Revista jurídica de igualdad de oportunidades entre mujeres y hombres, $\mathrm{n}^{\circ}$ 7, 2001, p. 21.

${ }^{8}$ No se trata ya de que de forma abrupta se produzca un cambio de residencia al hilo de un traslado ilícito, sino que hay cambios de residencia por motivos profesionales o simplemente vitales que plantean la necesidad de que el niño también la cambie, vid. S. Álvarez GonzÁLEz, "Traslado ilícito de menores, competencia judicial internacional y orden público", La Ley Unión Europea, $\mathrm{n}^{\circ} 33,2016$, versión on line.

9 Circular 6/2015, sobre aspectos civiles de la sustracción internacional de menores (https://www.fiscal.es/documents/ 20142/79c1a677-8c8f-bd7f-304a-0afac6aeeb25).

${ }^{10}$ La configuración jurídica de la sustracción internacional de menores se construye sobre otras instituciones como la filiación o la custodia, cuya determinación preliminar resulta necesaria a los efectos de concluir si el traslado o la retención ilícitos se han producido efectivamente: vid. C. AzcÁrraga Monzonís / P. Quinż́ Redondo, "Sustracción internacional de menores y Convenio de la Haya de 1980. Comentario de la sentencia de la Audiencia Provincial de Las Palmas (Sección 3ª́) núm. 377/2017, de 29 de junio", Cuadernos de derecho transnacional, vol. 10, nº 2, 2018, p. 800.

${ }^{11}$ Ese traslado internacional se utiliza para obtener la aplicación de las normas de Derecho internacional privado favorables para el progenitor que se apodera del niño. De este modo, los progenitores intentan conseguir por la vía de hecho la guarda y custodia que no se les confía de manera legal (Vid. I. Lorente Martínez, Sustracción internacional de menores. Estudio jurisprudencial, práctico y crítico, Dykinson, Madrid, 2019, p. 9).

${ }^{12}$ La ilicitud del traslado se identifica con una infracción de los derechos de custodia del menor regulados de conformidad 
6. Como es sabido, se reputa ilícito el traslado cuando se realice con infracción de un derecho de custodia atribuido con arreglo al Derecho del Estado en que el menor tenía su residencia antes del traslado $^{13}$. Por este motivo, a la vista del Convenio sobre los aspectos civiles de la sustracción internacional de menores, hecho en La Haya el 25 de octubre de $19800^{14}$ podrá pedir la restitución no sólo aquel progenitor que tenga un derecho de custodia en sentido estricto, sino también el progenitor que sea titular de un derecho de visitas. Es decir, el concepto «custodia» se corresponde con el derecho a elegir la residencia o domicilio del menor; esta matización, en opinión de ciertos autores, abre el espectro de la casuística a muchos más supuestos ${ }^{15}$.

7. A su vez, ha constituido piedra angular en esta materia, la Circular 6/2015 de la Fiscalía General del Estado. Fruto de su análisis, podemos atisbar que es extensa y en general bien fundamentada; de esta manera, en ella se debe encontrar la adecuada acogida en su aplicación práctica, esencialmente por parte de los Fiscales, sobre todo en lo que concierne a la prioritaria asistencia de los mismos a la vista ${ }^{16}$.

8. Por tanto, la sustracción que discurre desde la óptica puramente del Derecho internacional privado se produce cuando un progenitor altera deliberadamente la situación jurídica establecida respecto del menor, de manera que cuando lo traslada a otro país irregularmente, inevitablemente, hay un cambio de residencia ${ }^{17}$, suponiendo ello una situación compleja para retornar a la situación legal previa ${ }^{18}$. En efecto, se trata de una situación transfronteriza en la que el menor se ve implicado y demanda una especial protección jurídica ${ }^{19}$.

con la legislación del Estado de residencia habitual del menor: Vid. M. GonZÁlez MARIMÓN, "La sustracción internacional de menores en tiempos de Coronavirus: ¿una oportunidad para el progenitor sustractor?”, Actualidad jurídica iberoamericana, núm. extra 12, 2, 2020, p. 648.

13 J.J. Castelló Pastor, "Excepciones legales al retorno del menor en los supuestos de sustracción internacional", Cuadernos de derecho transnacional, vol. 10, $\mathrm{n}^{\circ} 1,2018$, p. 563.

${ }^{14}$ Instrumento de Ratificación del Convenio sobre los aspectos civiles de la sustracción internacional de menores, hecho en La Haya el 25 de octubre de 1980 (BOE n 202, de 24 de agosto de 1987). El número de Partes contratantes del Convenio son 101 a 19 de julio de 2019: https://www.hcch.net/es/instruments/conventions/status-table/?cid=24 En cuanto a los objetivos, características y relación con otros Convenios, vid. Informe explicativo de Dña. Elisa Pérez Vera: https://assets.hcch.net/ docs/43df3dd9-a2d5-406f-8fdc-80bc423cdd79.pdf

Una interpretación aislada del Convenio de la Haya de 1980, sin referencia a los tratados aplicables sobre derechos humanos, se ha convertido en una práctica de antaño (Vid. M.M. Celis Aguilar, "El papel controversial del TEDH en la interpretación del Convenio de La Haya de 25 de octubre de 1980 sobre los Aspectos Civiles de la Sustracción Internacional de Menores: Especial referencia a los casos Neulinger y Shuruk c. Suiza y X c. Letonia”, Anuario Colombiano de Derecho Internacional, vol. 13, 2020, p. 232).

${ }^{15}$ Asimismo, conviene constatar que, no es necesario que exista una previa resolución judicial que otorgue un determinado derecho de guarda o régimen de visitas, ya que lo que verdaderamente se protege es el efectivo ejercicio de un derecho de custodia o régimen de visitas, y con ello, el mantenimiento del statu quo del menor, lo cual puede suceder en una mera separación de hecho (Vid. M. SERRA MúÑoz, "La sustracción internacional de menores en España", Actualidad Jurídica Aranzadi, n 909, 2015, versión on line)

${ }^{16}$ Así pues, más que de prioritaria asistencia deberíamos hablar de obligatoriedad que ha de evitar hipotéticos futuros vicios de nulidad en los procesos ( $C f r$. F.J. ForCada Miranda, "El nuevo proceso español de restitución o retorno de menores en los supuestos de sustracción internacional. La decidida apuesta por la celeridad y la novedosa Circular de la Fiscalía 6/2015 (Parte II)", Bitácora Millennium DIPr: Derecho Internacional Privado, $\mathrm{n}^{\mathrm{o}} 3$ 3, 2016, p. 10).

${ }^{17}$ Un cambio de residencia habitual del menor como el que se produce como consecuencia de un secuestro internacional puede otorgar competencia con base en el Reglamento (CE) 2201/2003 a los tribunales de otro Estado miembro para pronunciarse acerca de los derechos de custodia y visita. No obstante, ante el peligro de legalizar una sustracción ilícita se contempla la prórroga de competencia otorgando la misma a los órganos del Estado de la residencia habitual del menor anterior al traslado, vid. M. SABIDO RodRíGUEZ, "La sustracción de menores en derecho internacional privado español: algunas novedades que introduce el Reglamento 2201/03", Anuario de la Facultad de Derecho, no 22, 2004, p. 319).

18 J. MuÑoz Cuesta, “Aspectos civiles de la sustracción internacional de menores”, Actualidad jurídica Aranzadi, n 934, 2017 , p. 6.

${ }^{19}$ Se están produciendo muchos casos en los que, bien el padre, o bien la madre de los hijos habidos en el matrimonio en crisis, o en la pareja en crisis, abandonan el domicilio familiar y se marchan a otro lugar. La devolución del menor o del hijo, si se trata de países fuera de la Unión Europea, en los que los derechos y la seguridad jurídica es relativa, se torna muy complicada (Vid. M.L. Soto RodríGuez, “El secuestro interparental”, Diario La Ley, $\mathrm{n}^{\circ}$ 8418, 2014, versión on line). 


\section{Marco regulatorio}

9. En sede de competencia judicial internacional, la regulación de la sustracción internacional de menores en la Unión Europea conlleva la aplicación conjunta del Reglamento (CE) $n^{\circ}$ 2201/2003 del Consejo, de 27 de noviembre de 2003, relativo a la competencia, el reconocimiento y la ejecución de resoluciones judiciales en materia matrimonial y de responsabilidad parental, por el que se deroga el Reglamento (CE) $n^{\circ} 1347 / 2000^{20} \mathrm{y}$ del Convenio sobre los aspectos civiles de la sustracción internacional de menores, hecho en La Haya el 25 de octubre de $1980^{21}$ para la tramitación de la orden de retorno en el Estado al que el menor ha sido trasladado ${ }^{22}$.

10. Conviene poner de manifiesto que, el Reglamento (CE) 2201/2003 quedará derogado a partir del 1 de agosto de 2022 por el Reglamento (UE) 2019/1111 del Consejo, de 25 de junio de 2019, relativo a la competencia, el reconocimiento y la ejecución de resoluciones en materia matrimonial y de responsabilidad parental, y sobre la sustracción internacional de menores ${ }^{23}$.

11. A estos dos textos normativos hay que añadir, por un lado, el Convenio Europeo relativo al reconocimiento y la ejecución de decisiones en materia de custodia de menores, así como al restablecimiento de dicha custodia, hecho en Luxemburgo el 20 de mayo de $1980^{24}$, el cual posee un papel secunda-

${ }^{20}$ DOUE $^{\circ} 338$, de 23 de diciembre de 2003. Se observa que la incorporación de la sustracción internacional de menores en el Reglamento (CE) 2201/2003 ha provocado que se trate de una materia comunitarizada, de forma que los Estados miembros tendrán que contar con una Propuesta de Decisión del Consejo para declarar la aceptación de la adhesión de Estados no miembros al Convenio de la Haya de 1980 en interés de la Comunidad (Vid. M. Herranz Ballesteros, "Los Tribunales de Estrasburgo y Luxemburgo ante la protección de los derechos fundamentales en supuestos de sustracción internacional de menores", Revista Española de Derecho Europeo, no 44, 2012, versión on line). El Reglamento (CE) 2201/2003 no sólo completa la regulación del Convenio de la Haya, sino que la mejora. Así, introduce en materia de competencia judicial internacional foros de competencia que no existían sino implícitamente en el citado Convenio de la Haya (Vid. I. ReIG FABADo, "El traslado ilícito de menores en la Unión Europea: retorno vs violencia familiar o doméstica", Cuadernos de derecho transnacional, vol. 10, $\mathrm{n}^{\circ}$ 1, 2018, p. 614).

${ }^{21}$ Una de las premisas básicas del Convenio es que el debate en torno al fondo del asunto, es decir, el derecho de custodia impugnado, debe iniciarse ante las autoridades competentes del Estado en el que el menor tenía su residencia habitual antes del traslado (Vid. F.J. Forcada Miranda, "La creciente complejidad del Derecho internacional de Familia", Familia y sucesiones: cuaderno jurídico, $\mathrm{n}^{\circ}$ 106, 2014, pp. 18-19). La finalidad de tal norma no es otra que garantizar la inmediata devolución del menor al Estado de la residencia habitual antes de ser trasladado ilícitamente a otro Estado parte. Ahora bien, este objetivo podría implicar que los intereses de los menores se vean quebrantados si la obligatoriedad impuesta por esta norma llegara a suponer a corto o largo plazo consecuencias perjudiciales para el menor (Vid. G. Moreno CoRDERO, "Las medidas de protección como garantía para un retorno seguro del menor sustraído o retenido ilícitamente: tensiones entre el grave riesgo y el interés superior del menor” en $\mathrm{M}^{\mathrm{a}}$.C. García Garnica / N. Marchal Escalona (dirs.), A. Quesada Páez / G. Moreno Cordero (coords.), Aproximación interdisciplinar a los retos actuales de protección de la infancia dentro y fuera de la familia, Thomson Reuters Aranzadi, Navarra, 2019, p. 632).

${ }_{22}$ Tanto la restitución como el retorno constituyen actuaciones que pueden realizarse individualmente, al término del proceso de sustracción, con independencia de la probable complementariedad de ambas en un momento ulterior (Vid. S. CALAZA LÓPEZ, "El nuevo régimen jurídico de la sustracción internacional de menores”, Diario La Ley, n 8564, 2015, versión on line).

${ }^{23}$ DOUE L 178/1, de 2 de julio de 2019. El nuevo texto del Reglamento 1111 es mucho más claro por lo que respecta a la relación entre instrumentos normativos. Contiene un precepto, el artículo 96, que claramente estipula que los traslados y retenciones ilícitos intracomunitarios seguirán rigiéndose por el Convenio de La Haya de 1980. Dicho precepto indica adicionalmente que los capítulos III y IV del Reglamento contienen disposiciones que completan a las del Convenio. Vale la pena resaltar que el nuevo Reglamento establece que las decisiones ejecutivas dictadas en un Estado de la Unión se ejecutan en los demás Estados sin declaración previa de ejecutividad: vid. el magnífico estudio de la novísima regulación en materia de sustracción internacional de menores en, C. González BeILfuss, "La sustracción de menores en el nuevo Reglamento 2019/1111” en S. Álvarez GonzÁlez / R. Arenas García / P. A. de Miguel Asensio / S. Sánchez Lorenzo / G. Stampa Casas (eds.), Relaciones transfronterizas, globalización y derecho. Homenaje al Prof. Dr. José Carlos Fernández Rozas, Thomson Reuters-Civitas, Navarra, 2020, pp. 383-398.

${ }^{24}$ Instrumento de ratificación de 9 de mayo de 1984 (BOE. $n^{\circ}$ 210, de 1 de septiembre de 1984). El reglamento destaca la esencialidad de la audiencia del menor en el proceso de restitución, vid. F. DE PAULA PUIG BLANES, “Aproximación al tratamiento de la sustracción internacional de menores en el Reglamento UE 2019/1111”, Actualidad Civil, núm. 4, 2020. Con relación a la ejecución, la principal novedad del Reglamento (UE) 2019/1111 es la eliminación general del exequátur, aunque ello no suponga la unificación de la ejecución de todo tipo de resoluciones. Antes, al contrario, se sigue concediendo un régimen privilegiado a determinadas resoluciones relativas al derecho de visita y a la restitución del menor. Por tanto, sigue siendo necesario diferenciar entre el sistema ordinario de ejecución y el privilegiado: vid. Pardo Iranzo, V., "Responsabilidad parental y sustracción internacional de menores: la ejecución en el nuevo Reglamento 2019/1111”, Diario La Ley, núm. 9629, 2020, versión on line. 
rio, tanto por el contenido concreto de sus soluciones, cuanto por el número de Estados contratantes que se encuentran vinculados por sus disposiciones ${ }^{25}$. Esta norma tiene como fin la lucha contra la sustracción ilícita a través del exequatur. Funciona del siguiente modo: cuando se ha infringido una sentencia que atribuye la custodia o el derecho de visita a ciertas personas, tales personas pueden instar en el país donde se encuentre el menor, el exequatur de la sentencia que establece el régimen de custodia o visita del menor. Logrado dicho exequatur, la sentencia o pronunciamiento judicial se ejecutará en el país donde se halla el menor, de modo que se puede ordenar el retorno del mismo al país desde donde fue ilícitamente traslada$\mathrm{do}^{26}$. Por otro, el Convenio entre el Reino de España y el de Marruecos en materia de derecho de custodia $y$ derecho de visita y devolución de menores, firmado en Madrid el 30 de mayo de 199727. En dicho texto, el criterio de la nacionalidad juega un papel importante, pues a tenor de su artículo 2 se aplicará a todo menor de dieciséis años no emancipado que posea la nacionalidad de uno de los dos Estados firmantes ${ }^{28}$.

12. Todas estas normas aspiran, en definitiva, a potenciar el regreso inmediato del menor que, en último término, suponga la satisfacción del interés superior de este, con el cumplimiento de las máximas garantías y en defensa de sus derechos más fundamentales ${ }^{29}$. Sin embargo, un consolidado sector doctrinal estima que, los instrumentos jurídicos sobre sustracción internacional de menores, tan necesarios y relevantes para evitar estos desplazamientos, corren el riesgo de dar lugar a situaciones materialmente injustas para el menor sustraído, si en su texto y aplicación no se atiende al contexto y a la realidad que comporta la violencia de género ${ }^{30}$.

13. Así las cosas, en esta contribución solo se analizará aquellos aspectos más destacados, en lo que respecta a la determinación de autoridades judiciales competentes, en base a lo regulado por el Reglamento (CE) 2201/2003 prestando especial focalización al foro de la residencia habitual del menor ante la inquietante situación del secuestro del menor en el marco privado internacional.

${ }^{25}$ S. Álvarez GonzÁlez, "Desplazamiento internacional de menores, procedimiento de retorno y tutela judicial efectiva", Derecho privado y Constitución, $\mathrm{n}^{\circ}$ 16, 2002, p. 61.

26 A-L. Calvo Caravaca / J. Carrascosa González, "Protección de menores" en A-L. Calvo Caravaca / J. Carrascosa GonZÁlEZ (dirs.), Derecho Internacional Privado, $18^{a}$ ed., vol. II, Comares, Granada, 2018, pp. 491-492.

${ }^{27} \mathrm{BOE} \mathrm{n}^{\circ}$ 150, de 24 de junio de 1997. Entrada en vigor del Convenio (BOE ${ }^{\circ}$ 151, de 25 de junio de 1999).

${ }^{28}$ E. Pías García, "Los Convenios de la Haya, Luxemburgo y Bilateral con Marruecos" en AA.VV., I Congreso jurídico sobre traslado ilícito de menores, Asociación para la recuperación de niños sacados de su país, Zaragoza, 2001, p. 69. Es de lamentar que el primer tratado bilateral específico concluido por España no se haya configurado como convenio doble, pues solo controla la competencia del tribunal de origen en el supuesto de que se trate de una resolución dictada en ausencia del demandado o de su representante legal ( $C f r$. M. MoYA Escudero, Aspectos internacionales del derecho de visita de los menores, Comares, Granada, 1998, p. 203-204).

${ }^{29}$ Debe entenderse que todas las medidas adoptadas por los jueces deben estar enfocadas a tramitar un regreso rápido del menor desde nuestro país, tanto cuando está aquí retenido ilícitamente, como cuando lo está en otro Estado miembro y las autoridades españolas ordenan su regreso a España (en cuanto Estado miembro de residencia habitual del menor antes de su traslado ilícito). En cambio, cuando el menor deba regresar a nuestro país desde otro Estado miembro en el que el menor está retenido ilícitamente, el regreso se llevará con arreglo a las medidas fijadas por su normativa interna, de ahí la importancia de la cooperación interestatal para que, en todo caso, el regreso del menor se lleve con éxito y con salvaguarda de su interés (Vid. R. Espinosa CAlabuig, "Traslado o retención ilícitos de menores tras la reforma de 2015: rapidez, especialización y... algunas ausencias", Revista española de derecho internacional, vol. 68, n 2, 2016, p. 350 y p. 352). Reflejo práctico de este planteamiento lo hallamos en la SAP de Tarragona, de 16 de diciembre de 2019 (ES:APT:2019:1683), en la que el menor ha permanecido dos años en Rumanía, donde se encuentra escolarizado y sin duda integrado en la vida del país de residencia, por lo que la atribución de la guarda al padre, pese a encontrarse éste en situación de atenderle y procurarle los cuidados y atenciones que precisa su hijo, se presenta como contraria a los intereses del menor, acostumbrado a vivir con su madre, en otro país, en otro entorno, y con cuyos vínculos afectivos se habrán visto sin duda reforzados durante estos años.

${ }^{30}$ C. Ruíz SutiL, "El menor sustraído ilícitamente en contextos internacionales de violencia machista" en Ma.C. GARCíA Garnica / N. Marchal Escalona (dirs.), A. Quesada PÁez / G. Moreno Cordero (coords.), Aproximación interdisciplinar a los retos actuales de protección de la infancia dentro y fuera de la familia, Thomson Reuters Aranzadi, Navarra, 2019, p. 632; M. Requejo IsIDRo, "Secuestro de menores y violencia doméstica en la Unión Europea", Anuario Español de Derecho Internacional Privado, $\mathrm{n}^{\circ}$ 6, 2006, pp. 179-194 E. RodríGuez PineAu, "Sustracción internacional de menores en casos de violencia familiar", en M.s. Quicios Molina / S. Álvarez Medina (dirs.), El derecho frente a la violencia dentro de la familia: un acercamiento multidisciplinar a la violencia de género y la protección de los hijos menores de edad, Aranzadi Thomson Reuters, Navarra, 2019, pp. 233-254. 


\section{Retrospección del foro de la residencia habitual del menor establecido por el Reglamento (CE) 2201/2003}

\section{Observación inicial}

14. El traslado del menor a fin de que permanezca en otro Estado con el consentimiento de ambos progenitores implicará la modificación de su residencia habitual y, en consecuencia, el cambio de las autoridades que serán competentes en su caso para decidir las cuestiones relativas al menor. Cuando el traslado del domicilio se produce con el acuerdo de ambos progenitores, la decisión parece adoptarse en un contexto en el que no hay crisis familiar y, por tanto, son asuntos que no plantean controversia jurídica. Son las situaciones de declive familiar las que, sin duda, suscitan los contratiempos más importantes cuando se trata de decidir uno de los elementos más importantes en la vida de un menor: el lugar de su domicilio y, sobre todo, cuando supone determinar si este ha de situarse en un Estado, a veces muy alejado, en todos los sentidos, de aquel en el que tiene su residencia habitual ${ }^{31}$.

15. El Reglamento (CE) 2201/2003 incluye en su articulado una serie de preceptos dedicados al desplazamiento ilícito de menores bajo las rúbricas «Competencia en caso de sustracción de menores», artículo 10, y «Restitución del menor», artículo $11^{32}$. Dicha norma europea ${ }^{33}$ ofrece un abanico de foros de competencia que tienen en su punto de mira el interés superior del menor $^{34} \mathrm{y}$ el principio de proximi-

${ }^{31}$ Cfr. M. Herranz Ballesteros, “Análisis del consentimiento del progenitor al desplazamiento o la retención del menor en un estado distinto al de su residencia habitual. Su interpretación en el auto de la Audiencia Provincial Barcelona (Sección $18^{\mathrm{a}}$ ) de 27 de noviembre", Cuadernos de derecho transnacional, vol. 11, nº 2, 2019, p. 648. De conformidad con la SAP de Murcia, de 23 de enero de 2020 (ES:APMU:2020:281), el cambio de residencia de la menor a Ucrania se produjo por decisión unilateral del padre sin consentimiento expreso de la progenitora materna que aunque conocía la voluntad e interés del padre al respecto, no asintió en ningún momento dicho traslado, cuya ejecución y efectividad le fue ocultada totalmente.

Hay que subrayar que, el Convenio de la Haya no es Convenio de custodia, sino de restitución, por lo que la resolución que deba ordenar la restitución se limita a acordar la devolución del menor al país en donde residía habitualmente para que sean las autoridades competentes las que, en su caso, decidan sobre la custodia. No se trata por tanto de valorar la situación actual en la que se encuentran los menores para decidir con cuál de los progenitores deben convivir: vid. SAP de Valencia, de 29 de junio de 2020 (ES:APV:2020:1719). ES:APV:2020:1719).

${ }^{32}$ Todo esquema del artículo 10 Reglamento (CE) 2201/2003 debe interpretarse a partir de tres líneas esenciales: la primera es el establecimiento de un sistema completo de competencia judicial internacional distribuido entre los tribunales del Estado de la residencia habitual anterior y los tribunales de la sustracción. La segunda es la ausencia de automatismo entre el cambio de residencia habitual y la asunción de competencia judicial internacionales por los tribunales de la nueva residencia. Y la tercera, es la desvinculación entre la decisión de no restitución y competencia judicial internacional de los tribunales de la sustracción. Estas tres líneas inciden claramente sobre la posible tendencia a utilizar el foro de la residencia habitual a efectos de la calificación de los traslados ilícitos (Cfr. P. JIMÉNEz BlANCO, Litigios sobre la custodia y sustracción internacional de menores, Marcial Pons, Madrid, 2008, pp. 150-151).

${ }_{33}$ El Reglamento (CE) 2201/2003 refuerza la competencia de las autoridades del Estado miembro de la residencia del niño anterior al traslado ilícito, llegando a establecer que, si se dicta un no retorno en el Estado miembro al que el niño fue trasladado, se ha de transmitir a las autoridades del Estado de la residencia anterior una copia de la resolución judicial de no restitución a fin de que pueda sustanciarse en dicho foro la cuestión de la custodia del menor (artículo 11.6). Si finalmente en el marco del proceso de custodia se decidiera el retorno del niño, tal decisión prevalecería sobre la dictada en el marco del procedimiento sobre la sustracción (artículo 11.8), vid. C. GonzÁLEZ BEILfuss, "La aplicación en España del Reglamento 2201/2003 en materia matrimonial y sobre la responsabilidad parental: señales de alarma", Revista jurídica de Catalunya, vol. 110, n 3, 2011 , p. 7.

${ }^{34}$ El interés superior del menor, como un concepto jurídico indeterminado, presenta ventajas e inconvenientes: en lo que respecta al aspecto positivo se debe resaltar el hecho de que ofrece la posibilidad de adaptar el problema en cuestión al caso específico que se pretende resolver, contexto que no impone al operador la obligación de actuar bajo parámetros determinados. No obstante, el aspecto negativo radica en la sujeción de la determinación a criterio del intérprete, lo que induce a que la solución se realice desde una perspectiva muy subjetiva, extremo que se traduce en la existencia de inseguridad jurídica (Vid. J.C. BARTOLOMÉ Cenzano, "Sobre la interpretación del interés superior del menor y su trascendencia en el derecho positivo español", Revista sobre la infancia y la adolescencia, $\mathrm{n}^{\mathrm{0}} 3,2012$, pp. 51-53). Se debe buscar el significado más nítido posible de lo que la locución quiere expresar, salvo que queramos que quede relegada a una mera fórmula carente de contenido y de verdadero significado jurídico; en realidad, la aclaración del concepto y de su cabal sentido resulta imprescindible en nuestro Derecho, toda vez que tanto la doctrina como la jurisprudencia, a pesar de su reiterada utilización, las más de las veces parecen dar vueltas sobre una idea intuitiva, que en muchas ocasiones sirve para justificar la solución que parece "justa" en el caso concreto, en lugar de mostrar

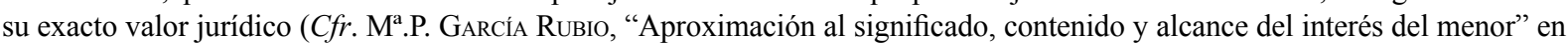
S. Álvarez González / R. Arenas García / P. A. de Miguel Asensio / S. Sánchez Lorenzo / G. Stampa Casas (eds.), Relaciones 
dad $^{35}$. La pretensión del legislador europeo es dejar de centrar la atención en los progenitores para poner todo el énfasis en la protección de los menores ${ }^{36}$.

16. De esta suerte, la norma objeto de análisis ${ }^{37}$ otorga un destacado papel procesal al menor siendo la residencia habitual el criterio de determinación de foros competenciales ${ }^{38}$, de modo que, el principal factor vinculante de la norma comunitaria es la localización de aquella ${ }^{39}$.

En consecuencia, la residencia habitual del menor es el eje gravitatorio del sistema que decide la competencia judicial internacional, además del carácter lícito o ilícito del traslado o la retención y, en último término, y en función de su concreción o modificación si se producirá finalmente o no el retorno inmediato del menor ${ }^{40}$.

\section{Perspectiva jurisprudencial -europea y española- con comunicación bidireccional}

17. Resulta preciso poner de manifiesto que, la interpretación del concepto de residencia habitual es objeto de polémica ${ }^{41}$ pues ha tenido que ser resuelta en atención a las circunstancias concretas que

transfronterizas, globalización y derecho. Homenaje al Prof. Dr. José Carlos Fernández Rozas, Thomson Reuters-Civitas, Navarra, 2020, pp. 1075-1090). Como concepto jurídico indeterminado no debe olvidarse que, existe siempre en el mismo un núcleo o zona de certeza en su concreción, vid. A. FERNÁNDEZ PÉREZ, "Aproximación al interés superior del menor en el derecho internacional privado español”, Boletín Mexicano de Derecho Comparado, vol. 50, núm. 151, 2018, p. 122.

${ }^{35}$ El artículo 15 Reglamento (CE) 2201/2003 es una excepción al resto de las normas de competencia del Reglamento; se refiere a un tribunal mejor situado que no es uno de los que ya pueden ser competentes; y singularmente no lo es el de la residencia habitual del menor (Vid. S. Álvarez GonzÁlez, "De nuevo sobre la interpretación y alcance del artículo 15 del Reglamento Bruselas II bis. (Una alternativa efímera a la STJ de 4 de octubre de 2018)", La Ley Unión Europea, nº 66, 2019, versión on line).

${ }^{36}$ Su condición de parte débil ha contribuido a sensibilizar los distintos contextos jurídicos; por esta razón, la regulación material que cada ordenamiento dedica a las relaciones entre padres e hijos se enmarcan en la protección del menor (Vid. $\mathrm{M}^{\mathrm{a}}$.P. Diago Diago, "La mundialización y las relaciones jurídicas entre padres e hijos" en A-L. Calvo Caravaca / J.L. Iriarte Ángel (eds.), Mundialización y familia, Colex, Madrid, 2001, p. 143).

${ }^{37}$ La complejidad del modelo empleado por el Reglamento (CE) 2201/2003 quedará justificada si contribuye efectivamente a una rápida y mejor solución del secuestro internacional de menores en la UE (Vid. B. CAMPUZANo Díaz, "La política legislativa de la UE en DIPr de familia. Una valoración de conjunto", Cuadernos de derecho transnacional, vol. 5, no 2, 2013, p. 255).

38 S. Ortiz Herrera, "Tratamiento de la responsabilidad parental en el Reglamento 2201/2003: un avance hacia la integración y armonización del derecho civil en Europa”, RDUNED. Revista de derecho UNED, nº 3, 2008, pp. 191-192 M. GoNZÁLEZ MARIMÓN, "Un paso más en el proceso de armonización del Derecho Privado Europeo: la concreción por el TJUE del concepto de residencia habitual del menor recogido en el Reglamento Bruselas II bis", Revista Boliviana de Derecho, núm. 30, 2020, pp. 470-495.

${ }^{39}$ La residencia habitual juega un papel fundamental en los Reglamentos de la Unión Europea y en los Convenios internacionales en los que participa la Unión Europea, ya sea directamente o a través de sus Estados miembros. Sin embargo, con el fin de preservar su carácter fáctico se ha optado por no definir este concepto, dejando que sean las autoridades encargadas de aplicar cada norma las que lo concreten en función de las circunstancias del caso (Vid. B. CAmpuzAno DíAz, "Una nueva sentencia del TJUE sobre el concepto de residencia habitual en el marco del Reglamento 2201/2003: sentencia de 17 de octubre de 2018, UD y XB, AS. 393/18 PPU”, Cuadernos de derecho transnacional, vol. 11, nº 2, 2019, p. 466; C. MARín PedreÑo, Sustracción internacional de menores y proceso legal para la restitución del menor, Editorial Ley 57, Málaga, 2015, p. 25).

${ }^{40}$ Piénsese que este elemento fundamenta la demanda de restitución por cuanto esta solo prosperará si el menor tenía su residencia habitual inmediatamente antes del traslado o la retención ilícitos en el Estado donde se presenta (Cfr. I. ReIG FABADO, "La construcción del concepto autónomo de residencia habitual del menor en los supuestos de sustracción internacional de menores", Cuadernos de derecho transnacional, vol. 11, n 1, 2019, p. 887). La preferencia por la residencia habitual de la persona responde a la idea de "integración social". Además, constituye un criterio dotado de un aceptable nivel de estabilidad jurídica, pues la Ley aplicable no cambia, aunque las personas viajen por el mundo, trasladen temporalmente su residencia a otro país, o cambien de nacionalidad. Igualmente, es fácilmente comprobable por las autoridades y por terceros, dejando al margen casos difíciles que siempre surgen, vid. excelentes reflexiones de A-L. CALVo CARAVACA, "El Derecho internacional privado de la Unión Europea. Valores y principios regulativos", Cadernos do Programa de Pós-Graduação em Direito PPGDir./ UFRGS, Vol. XV, núm. 1, 2020, pp. 22-23.

${ }^{41}$ En sede de Ley aplicable, la utilización del criterio de la residencia habitual ofrece a priori dos ventajas. Por una parte, permite obviar las complicaciones derivadas de la conservación de la nacionalidad extranjera en el Estado de acogida o de la adquisición de la nacionalidad de éste. Y ello porque, por otra parte, esta conexión contiene un matiz de mayor igualdad en orden a la designación del ordenamiento aplicable por cuanto somete a todos los residentes habitualmente en un Estado (nacionales y extranjeros) al mismo sistema jurídico lo que implica, en definitiva, su integración -al menos formal- en la sociedad de acogida. Por tanto, se puede afirmar que las normas europeas en el vasto campo del Derecho de familia se sustentan en la 
concurrían en diversos asuntos planteados ante los juzgados y tribunales ${ }^{42}$. De este modo, la residencia habitual es una "noción fáctica"

18. Sobre esta cuestión, es interesante resaltar la variación que se ha producido respecto de la noción de residencia habitual en la jurisprudencia del Tribunal de Justicia de la Unión Europea ${ }^{44}$. No cabe duda que, el tinte que impregna tal parámetro se sustenta en el lugar en el que el menor tenga una cierta integración social y familiar.

En tal sentido, el Tribunal de Justicia europeo ha declarado que, además de la presencia física del menor en un Estado miembro ${ }^{45}$, deben tenerse en cuenta otros factores que indiquen que dicha presencia no tiene en absoluto carácter temporal u ocasional ${ }^{46}$. Inclusive, el Tribunal de Luxemburgo entendemos que presta cierta atención al valorar que la determinación de la residencia habitual de un menor en un Estado miembro específico requiere, como mínimo, que el menor haya estado físicamente presente en ese Estado miembro ${ }^{47}$. Conviene evocar que, cuando no se da la presencia física del propio

utilización de la residencia habitual en detrimento de la nacionalidad (Vid. A. RoDRíGUEz BENOT, "El criterio de conexión para determinar la ley personal: un renovado debate en Derecho Internacional Privado", Cuadernos de derecho transnacional, vol. 2, no 1,2010, p. 193 у p. 198).

${ }^{42}$ Como muy buen apunta la doctrina especializada, se desprende la relevancia de establecer una conveniente definición, pues cada instrumento legal emplea un concepto de residencia habitual autónomo y propio y que tampoco ha sido interpretado de manera coincidente por la jurisprudencia. Vid. Ma .C. CHÉLIz INGLÉs, La sustracción internacional de menores y la mediación. Retos y vías prácticas de solución, Tirant lo Blanch, Valencia, 2018, pp. 44-46. Existen autores que abogan por establecer un concepto de residencia habitual con perfiles europeos en los supuestos en los que la residencia habitual de las partes no es única y puede desarrollarse en diversos estados de la Unión Europea (Vid. A. Del Ser López / D. CArrizo Aguado, "Reglas de competencia judicial internacional en materia de responsabilidad parental: análisis del foro de la "residencia habitual del menor" y estudio de la «competencia residual»", Revista Aranzadi Unión Europea, n 10, 2019, p. 67; L.A. PÉrez MARTín, "Determinación y trascendencia de la residencia habitual en las crisis familiares internacionales" en M. GUZMÁN ZAPATER / M. Herranz Ballesteros (dirs.), Crisis matrimoniales internacionales y sus efectos derecho español y de la Unión Europea. Estudio normativo y jurisprudencial, Tirant lo Blanch, Valencia, 2018, p. 959). La conceptualización de dicho término ha sido orquestada por el Tribunal de Justicia de la Unión, vid. J.M. DE LA Rosa CorTina, Sustracción parental de menores. Aspectos civiles, penales, procesales e internacionales, Tirant lo Blanch, Valencia, 2010, p. 200.

${ }^{43}$ El menor se convierte en el centro del proceso, por eso, el foro de la residencia habitual del menor en un Estado miembro desarrolla una idea de litigación económica o economía procesal-jurisdiccional ( $C f r$. J. CARRAscosa GonzÁLEz, "Litigación internacional, responsabilidad parental y foro de la residencia habitual del menor en un estado miembro. Un estudio jurisprudencial” en Ma .A. Cebrián Salvat / I. Lorente Martínez (dirs.), Protección de menores y derecho internacional privado, Comares, Granada, 2019, pp. 322-323).

${ }^{44}$ En cualquier caso, una idea que permanece inalterable es en aquellos supuestos en los que no se considera de ninguna forma la decisión y voluntad de los padres a la hora de fijar la residencia. Como muestra de la evolución que se ha producido en la jurisprudencia del Tribunal de Luxemburgo en su STJUE de 2 de abril de 2009, asunto C-523/07, $A$ (EU:C:2009:225) el juez europeo afirmó que la residencia habitual de un menor, en el sentido del apartado 1 del artículo 8 Reglamento (CE) 2201/2003, debe determinarse sobre la base de un conjunto de circunstancias de hecho que son particulares en cada caso. En dicho asunto, el menor había sido desplazado por sus padres de un Estado miembro a otro y, poco después, se había asumido su guarda. Igualmente, en la STJUE de 22 de diciembre de 2010, asunto C-497/10 PPU, Mercredi (ECLI:EU:C:2010:829) el Tribunal reiteró que la residencia de un lactante de dos meses corresponde al lugar que revela una cierta integración del menor en un entorno social y familiar.

${ }^{45}$ Por el hecho de que el menor no disponga de una residencia habitual debido a la falta de presencia física en un Estado miembro, ni la existencia de órganos jurisdiccionales de un Estado miembro mejor situados para conocer de los asuntos de ese menor aun cuando este no haya residido nunca en ese Estado, permitirán determinar la residencia habitual del menor en un Estado miembro en el que nunca ha estado presente: STJUE de 17 de octubre de 2018, asunto C-393/18 PPU, UD (EU:C:2018:835). Un notable estudio del mismo, vid. L.A. Pérez Martín, "Residencia habitual de los menores y vulneración de derechos fundamentales. Sentencia del Tribunal de Justicia de 17 de octubre de 2018, asunto C-393/18, PPU", La Ley Unión Europea, $\mathrm{n}^{\circ} 66,2019$.

${ }^{46}$ Entre esos factores figuran la duración, la regularidad, las condiciones y las razones de la permanencia del menor en el territorio de un Estado miembro y la nacionalidad del menor: Vid. STJUE de 2 de abril de 2009, asunto C-523/07, A (EU:C:2009:225). Si bien, las causas pertinentes varían en función de la edad del menor: Vid. STJUE de 22 de diciembre de 2010, asunto C-497/10 PPU, Mercredi (EU:C:2010:829).

${ }^{47}$ STJUE de febrero de 2017, asunto C-499/15, W y V (EU:C:2017:118). En torno al mismo, vid. S. Álvarez GonzÁlez, "Competencia judicial internacional para la modificación de sentencia en materia de responsabilidad parental y de obligaciones alimenticias. STJUE de 15 de febrero de 2017, asunto C-499/15: W y V", La Ley Unión Europea, no 47, 2017; E. ViganotTI, "La notion de "résidence habituelle" de l'enfant selon la CJUE", Gazette du Palais, no 40, 2018 pp. 24-26; L. Idot, "Compétence en matière de responsabilité parentale", Europe, $n^{0} 12,2018$, pp. 43-44. 
menor en el Estado miembro de que se trate, no se puede conceder una importancia preponderante, para la interpretación del concepto de «residencia habitual», a circunstancias como la intención del progenitor que asume de hecho la guarda del menor o la eventual residencia habitual de uno u otro progenitor en dicho Estado miembro, en perjuicio de consideraciones geográficas objetivas, so pena de pasar por alto la intención del legislador de la Unión ${ }^{48}$.

A pesar de todo esto, en aquellos supuestos en los que el menor se encontraba en un Estado diferente con anterioridad al traslado o retención ilícita, el «centro social de vida» será el determinante para su enmarcación como residencia habitual ${ }^{49}$.

19. A nivel interno, entre los últimos pronunciamientos analizados, los jueces españoles prestan atención a cuestiones tales como, el arraigo del menor, sus costumbres, hábitos, colegio, amigos... ${ }^{50}$. También, situaciones como el alta en el sistema nacional de salud, el centro donde ha cursado sus estudios antes de la sustracción e incluso donde está matriculado en el momento de autos ${ }^{51}$. De manera exhaustiva, en la Sentencia de la Audiencia Provincial de Barcelona de 14 de noviembre de 2019 (ES:APB:2019:13677) el juez pondera elementos subjetivos de la menor: ... está feliz y encantada con todas las actividades que hace en la escuela, se despide del adulto con ganas de compartir momentos con todos los compañeros, con los que es muy cariñosa, en las actividades participa siempre, es sociable, divertida, simpática y cariñosa y ofrece una actitud muy positiva. En cambio, en la Sentencia de la Audiencia Provincial de A Coruña de 5 de julio de 2019 (ES:APC:2019:1546) la situación de permanencia y de convivencia de ambos progenitores en Bélgica desde años antes del nacimiento de la menor es lo que determina su residencia habitual en el momento del traslado a España. Sugerente deviene la reciente Sentencia de la Audiencia Provincial de Girona de 13 de diciembre de 2019 (ES:APGI:2019:1950) en la que con pleno conocimiento y anuencia del progenitor varón, ambos menores residen en el Reino Unido junto a la madre donde desarrollan su vida con normalidad, incluyendo que en ese país reciben las visitas de su padre cada dos o tres semanas. Ambos progenitores pactan que solo estarán en España en el periodo de vacaciones con el motivo de estar con el padre. Si bien, en el último verano el padre no retorna a los menores al Reino Unido con motivo de la imputación a la progenitora de desatención y dejadez en relación al cuidado de los menores, malos hábitos higiénicos, problemas en la boca, suciedad, desorden...Inteligentemente, la madre acredita que los menores están inscritos en un Centro de Salud del Reino Unido, que permanecen escolarizados y obtienen buenos resultados académicos; además, aporta informes de los médicos que atienden a los menores en los que se avala esta posición. Por si fuera poco, respalda su argumentación con la existencia de una resolución del Tribunal de Familia de Preston, localidad del Reino Unido donde residen, en la que se manifiesta competente jurisdiccionalmente dicho órgano por tener los menores su residencia habitual en Reino Unido.

20. A la postre de lo referido hasta el momento, sin duda alguna, la determinación del lugar de residencia habitual del menor dependerá de las circunstancias propias de cada supuesto ${ }^{52}$. Empero,

${ }^{48}$ STJUE de 28 de junio de 2018, asunto C-512/17, HR (EU:C:2018:513). Al respecto, vid. P. Gruber, "Der gewöhnliche Aufenthalt von Säuglingen und Kleinkindern (zu EuGH, 28.6.2018,- C-512/17, unten S. 248, Nr. 21)", IPRax: Praxis des Internationalen Privat- und Verfahrensrechts, vol. 39, no 3, 2019 pp. 217-221.

${ }^{49} \mathrm{Vid}$. en este sentido, C.Mª CAamiña Domínguez, La sustracción de menores en la Unión Europea, Colex, Madrid, 2010, p. 47.

${ }^{50}$ SAP de Segovia de 5 de diciembre de 2019 (ES:APSG:2019:723).

${ }^{51}$ Estos fundamentos clarifican que el menor estaba integrado en el Reino Unido, a pesar de que la madre sustractora empadronó al menor, pero sagazmente, el juez competente estimó una alteración del concepto autónomo de residencia habitual: Vid. SAP de Palencia de 20 de abril de 2018 (ES:APP:2018:217).

${ }^{52}$ Exempli gratia, en la STJUE de 8 de junio de 2017, asunto C-111/17, OL y PQ (ECLI:EU:C:2017:436) la menor nació en un determinado Estado miembro por voluntad común de sus padres y que, inmediatamente antes de la retención alegada, había permanecido en dicho Estado durante cinco meses consecutivos con su madre, en el seno de la familia paterna de ésta, sin haber abandonado nunca el territorio de ese Estado. En tales circunstancias, adoptar como criterio preponderante la intención inicial de los progenitores de que la madre regresase acompañada de la menor a un segundo Estado miembro, que era el de la residencia habitual de aquéllos antes del nacimiento de la menor, estableciendo con ello de hecho una regla general y abstracta de que la residencia habitual de un lactante es necesariamente la de sus padres, iría más allá de los límites del concepto de 
ciertos criterios meramente formales podrán ser tomados en consideración para determinar el lugar de residencia habitual del menor, pero sólo en la medida en la que reflejen una auténtica residencia habitual basada en una integración real del mismo en una concreta sociedad estatal ${ }^{53}$.

Así las cosas, hay autores que entienden que mantener la competencia a favor de los tribunales de la residencia habitual del menor puede parecer proteger al titular del derecho de visita, pero, sin duda, a quien beneficia es al menor que verá más fácilmente materializado su derecho a mantener un contacto con ese titular del derecho de visita ${ }^{54}$.

21. Incluso, el poder legislativo europeo ha decidido reforzar el mecanismo de la restitución entre los Estados miembros ${ }^{55}$, incorporando una obligación de retorno [artículo 11.4 Reglamento (CE) 2201/2003] así como un mecanismo de "última palabra" [artículos 11.6 a 11.8 Reglamento (CE) 2201/2003]. Este último supone que, una vez decidido por las autoridades del Estado a donde ha sido trasladado o retenido el menor que este no debe volver al Estado de su residencia habitual, la autoridad del Estado de su residencia habitual previa al traslado o retención puede decidir sobre la custodia del menor, adoptando una medida que suponga su retorno ${ }^{56}$. Es decir, se permite que el tribunal de la residencia habitual del menor tenga la última decisión y pueda revisar la adoptada por el tribunal de otro Estado miembro donde se encuentra el niño ${ }^{57}$.

22. Dada la necesidad de asegurar la protección del interés superior del menor, escollo que será examinado en el siguiente apartado, al evaluar todas las circunstancias específicas de cada caso, cuando el traslado del menor ha tenido lugar conforme a una resolución judicial ejecutiva provisional, que fue revocada a posteriori por una resolución judicial que fijaba la residencia del menor en el domicilio del progenitor que permanece en el Estado miembro de origen, el órgano jurisdiccional del Estado miembro al que fue trasladado el menor, debe comprobar, si el menor aún tenía su residencia habitual en el Estado miembro de origen inmediatamente antes de la retención ilícita. En esa evaluación se debe tener en cuenta el hecho de que la resolución judicial que autorizaba el traslado podía ser ejecutada provisionalmente y resultar recurrida en apelación ${ }^{58}$.

«residencia habitual», en el sentido del Reglamento (CE) 2201/2003, y sería contrario a la lógica interna, a la eficacia y a la finalidad del procedimiento de restitución.

${ }^{53}$ Las inscripciones registrales o en el padrón municipal de habitantes no presentan, por sí solas, ningún valor material que revele una residencia habitual con el país del que se trate, vid. J. CARRASCOSA GonzÁLEZ, "Litigación internacional, responsabilidad parental y foro de la residencia habitual del menor en un estado miembro. Un estudio jurisprudencial" en Ma .A. CEBRIÁN SALvat / I. Lorente Martínez (dirs.), Protección de menores y derecho internacional privado, Comares, Granada, 2019, pp. $307-323$.

${ }^{54}$ P. Maestre Casas, "Sustracción y restitución internacional de menores" en E. Llamas Pombo (coord.), Nuevos conflictos del Derecho de familia, Wolters Kluwer, Madrid, 2009, p. 520.

${ }^{55}$ C. Otero García-Castrillón / C.I. Cordero Álvarez, Protection of abducting mothers in return proceedings: intersection between domestic violence and parental child abduction, POAM Proyect, January 2020, Spanish National Report, 2020, pp. 10-11: https://research.abdn.ac.uk/wp-content/uploads/sites/15/2020/02/National-report_Spain.pdf. La regla general es la inmediata restitución del menor al Estado de su residencia habitual y así restaurar el status quo anterior a la sustracción tan pronto como sea posible con el fin de evitar los efectos dañinos del traslado o retención ilícita en su interés superior y la excepción es la no restitución: vid. N. GonZÁLEZ MARTín, "Mediación ante el "grave riesgo" en la sustracción internacional parental de menores", en M.S. Quicios Molina / S. Álvarez Medina (dirs.), El derecho frente a la violencia dentro de la familia: un acercamiento multidisciplinar a la violencia de género y la protección de los hijos menores de edad, Aranzadi Thomson Reuters, Navarra, 2019, p. 257.

${ }^{56}$ Es importante conseguir procesos nacionales de restitución más rápidos, con explícitas y más estrictas previsiones legales que aseguren que las peticiones de retorno se procesan de modo urgente en todas las instancias y en la fase de ejecución, se han de establecer mejores medidas de protección provisionales que aseguren el retorno del menor y, en su caso, del acompañante, y debe haber regulación de específicas medidas relativas a los procesos de ejecución de órdenes de retorno con límites legales y con la promoción del cumplimiento voluntario, vid. al respecto, F.J. ForCADA MIRANDA, "Carencias, necesidades y conflictos de la sustracción internacional de menores y el novedoso marco legal español", Revista española de derecho internacional, vol. 68, n 2, 2016, p. 340; N. MaLlandrich Miret, "El procedimiento de restitución o retorno de menores ilícitamente sustraídos en la LEC", Justicia: revista de derecho procesal, $\mathrm{n}^{\circ} 1,2019$, pp. 267-320.

${ }^{57}$ E. Rodríguez Pineau, "La oposición al retorno del menor secuestrado: movimientos en Bruselas y La Haya", Revista electrónica de estudios internacionales (REEI), $\mathrm{n}^{\circ} 35,2018$, p. 69.

${ }^{58}$ STJUE de 9 de octubre de 2014, asunto C376/14 PPU, C y $M$ (EU:C:2014:2268). La determinación del interés superior del niño no es, pues, fruto de una apreciación subjetiva y discrecional, sino de la aplicación reglada al caso concreto de un 
De igual modo, la sustracción ilícita de un menor no debería, en principio, tener la consecuencia de transferir la competencia de los órganos jurisdiccionales del Estado miembro en el que residía habitualmente el menor inmediatamente antes de su traslado a los del Estado miembro al que el menor ha sido trasladado ${ }^{59}$. Con todo, por regla general la competencia judicial internacional para conocer del fondo del asunto es conservada por los tribunales del país de origen, siendo excepcional la pérdida de dicha competencia en favor de los tribunales del país de la sustracción ${ }^{60}$.

23. En definitiva, son los órganos jurisdiccionales del Estado miembro de la residencia habitual del menor los que se encuentran en mejor situación para conocer de cualquier pretensión relativa a la responsabilidad parental, más aún en supuestos tan sensibles como el traslado y retención ilícitos de un menor ${ }^{61}$. Es decir, la proximidad será el elemento que garantice el interés superior del menor ${ }^{62}$. Sin lugar a dudas, la preferencia del legislador europeo por el criterio «residencia habitual del menor» como factor para precisar la competencia judicial internacional constituye un acierto de política jurídica, pues refuerza, potencia y preserva el principio favor minoris en el cambiante y líquido escenario jurídico internacional ${ }^{63}$.

\section{Límite de maniobra para el juez: acatamiento del principio «favor minoris»}

24. A este respecto, debe entenderse que, el concepto de «residencia habitual», en el marco del Reglamento (CE) 2201/2003, ha de ser interpretado en función del interés superior del menor ${ }^{64}$

concepto jurídico indeterminado, vid. C. MARTínez GARcíA, El derecho a crecer en familia. La necesaria transformación del sistema de protección a la infancia en España, Aldeas Infantiles SOS, 2020, p. 40.

59 Ello conlleva un doble examen de la cuestión de la restitución del menor, que garantiza de este modo un mejor fundamento de la resolución y una mayor protección de los intereses del menor: Vid. STJUE de 1 de julio de 2010 , asunto C-211/10 PPU, Povse (EU:C:2010:400).

${ }^{60}$ En la valoración que el tribunal competente ha de hacer de la integración del menor, a la hora de dictar una resolución en materia de sustracción internacional que responda al interés superior del mismo, es preciso tener presente el alcance de la competencia de tal tribunal, vid. C.M '. CAAMiÑA DomínguEz, "El interés superior del menor: la integración en el nuevo medio", Cuadernos de derecho transnacional, vol. 8, n 2, 2016, pp. 90-91.

61 L. CARpaneto, "La sottrazione internazionale di minori" en AA.VV., La Convenzione delle Nazioni Unite sui diritti dell'infanzia e dell'adolescenza: conquiste e prospettive a 30 anni dall'adozione, Autorità garante per l'infanzia e l'adolescenza, Italia, 2019, p. 423; J. Martínez CALvo / Ma .J. SÁnchez CAno, "Estudio jurídico del caso de Juana Rivas y Francesco Arcuri desde la perspectiva del Derecho Internacional Privado y del Derecho Civil”, Cuadernos de derecho transnacional, vol. 12, n 1 , 2020, p. 743 E. Dubout, “The European Form of Family Life: The Case of EU Citizenship”, European Papers, vol. 5, núm. 1, 2020, p. 24-25.

62 O. Lopes Pegna, "Tecniche internazionalprivatistiche a tutela del superiore interesse del minore: flessibilità alla ricerca del miglior risultato nel caso concreto" en AA.VV., La Convenzione delle Nazioni Unite sui diritti dell'infanzia e dell'adolescenza: conquiste e prospettive a 30 anni dall'adozione, Autorità garante per l'infanzia e l'adolescenza, Italia, 2019 , p. 372.

${ }^{63}$ Los tribunales de la residencia habitual del menor son los que conocen de primera mano el medio social en el que vive el menor; tales tribunales operan con menor carga procesal que la que tendrán los tribunales de un país que no fuera el de la residencia habitual del menor. Además, son los tribunales que pueden practicar pruebas relevantes con un menor coste e inmediatez. Igualmente, son los tribunales que permiten disuadir un traslado ilícito internacional pues continúan conservando su competencia a pesar de dicho traslado ilícito (Vid. J. CARRAscosa GonzÁlez, "Protección de menores extranjeros en España. El criterio residencia habitual del menor" en J.A. Cobacho Gómez / F. Legaz Cervantes (dirs.), B. Andreu Martínez / A. LeciñenA Ibarra / J. Martínez moya (coords.), Protección civil y penal de los menores y de las personas mayores vulnerables en España, Thomson Reuters Aranzadi, Navarra, 2018, p. 476 y p. 492).

${ }^{64}$ Conforme con el criterio de proximidad, privilegiado por el legislador de la Unión en el Reglamento (CE) 2201/2003, para garantizar que se tenga en cuenta el interés superior del menor, el Tribunal de Luxemburgo estima que, las eventuales decisiones que atañan a este sean adoptadas por los órganos jurisdiccionales del Estado miembro en el que el menor reside de forma continua desde su nacimiento, vid. STJUE de 23 de diciembre de 2009, asunto C403/09 PPU, Detiček (EU:C:2009:810) y STJUE de 15 de julio de 2010, asunto C-256/09, Purrucker (EU:C:2010:437). Los instrumentos internacionales en materia de sustracción internacional de menores identifican el interés del menor con el restablecimiento del statuo quo anterior mediante su retorno inmediato adoptando así una interpretación general y abstracta de este principio (vid. M. GONZÁLEZ MARIMÓN, "El principio del interés superior en supuestos de sustracción ilícita internacional: la jurisprudencia de TJUE y TEDH” en Ma .C. García Garnica / N. Marchal Escalona (dirs.), A. Quesada PÁez / G. Moreno Cordero (coords.), Aproximación interdisciplinar a los retos actuales de protección de la infancia dentro y fuera de la familia, Thomson Reuters Aranzadi, Navarra, 2019, p. 657). 
como un criterio de ponderación abierto y un principio necesario inspirador de todas las actuaciones judiciales ${ }^{65}$.

25. Entre los elementos de interés de protección del menor en tales situaciones se han destacado por el Tribunal Supremo español ${ }^{66}$ aspectos como la valoración del apego que tiene el menor con quien solicita el traslado, la aptitud del progenitor para conseguir al menor bienestar, así como procurarle un entorno familiar, económico y de protección adecuado, el establecimiento de un apropiado régimen de visitas que venga a paliar la limitación de las relaciones del menor con el progenitor que no se traslada y el otorgamiento de opinión de los menores ${ }^{67}$. A tenor de esta última consideración, no debe caer en baldío que los menores pueden expresar su opinión libremente y que su parecer puede ser tenido en cuenta para los asuntos que les afecten, si bien únicamente en función de su edad y madurez ${ }^{68}$. Pero ello implica que, incumbe al juez que haya de resolver sobre la restitución del menor apreciar la oportunidad de tal audiencia, en la medida en que los conflictos que hacen necesaria una decisión en cuanto a la atribución de la custodia de un menor a uno de los progenitores, y las correspondientes tensiones, constituyen situaciones en las que la audiencia del menor, por cuanto requiere, llegado el caso, puede resultar inapropiada, incluso perjudicial para la salud psíquica del niño, pues a menudo se ve sometido a dichas tensiones y padece sus efectos dañinos ${ }^{69}$.

26. Sobre este particular es preciso apuntar que, el respeto del principio del interés superior del menor debe considerarse como regla general con el fin de que el menor retorne con celeridad ${ }^{70}$ al lugar

${ }^{65}$ J.C. Bartolomé Cenzano, "Sobre la interpretación del interés superior del menor y su trascendencia en el derecho positivo español”, Revista sobre la infancia y la adolescencia, n 3, 2012, p. 50; Mª .C. CHÉLIZ InGLÉs, "El interés superior del niño en los supuestos de sustracción internacional de menores. Análisis jurisprudencial en el marco del convenio de la Haya 1980" en S. SAnz Caballero (dir.), El interés superior del niño en la jurisprudencia internacional, comparada y española, Navarra, Thomson Reuters Aranzadi, 2017, p. 342.

${ }^{66}$ En el ámbito de los mecanismos de restitución, cabe referirse a dos cuestiones problemáticas: a) la inadmisibilidad del recurso de casación; y b) la denominada regla de "competencia judicial internacional negativa, vid. C.Ma . CAAMIÑa DomíngueZ, "Sustracción internacional de menores. Aplicación por el Tribunal Supremo de los instrumentos internacionales vigentes para España" en A-L. Calvo Caravaca / J. Carrascosa GonzÁlez (dirs.), El Tribunal Supremo y el Derecho internacional privado, vol. 2, Rapid Color, Murcia, 2019, pp. 587-605.

${ }^{67} \mathrm{Vid}$. la sólida jurisprudencia del Tribunal Supremo en torno al interés de protección del menor en caso de traslado de su domicilio al extranjero junto con unas magníficas valoraciones en, M. Herranz Ballesteros, "Traslado de domicilio del menor a otro país. Doctrina del Tribunal Supremo" en A-L. Calvo Caravaca / J. Carrascosa González (dirs.), El Tribunal Supremo y el Derecho internacional privado, vol. 2, Rapid Color, Murcia, 2019, pp. 567-586. En estos mismos términos queda recogido en la reciente Resolución del Parlamento Europeo, de 8 de julio de 2020, sobre la sustracción internacional y nacional de menores de la Unión por sus progenitores en Japón (2020/2621(RSP)).

${ }^{68}$ El tiempo biológico no puede medirse según criterios generales, dada la estructura intelectual y psicológica de los menores y la rapidez con la que esta evoluciona: vid. STJUE de 11 de julio de 2008, asunto C-195/08 PPU, asunto Rinau (EU:C:2008:406). La decisión adoptada en el asunto Rinau es la primera que el Tribunal de Justicia de la Unión Europea canaliza procesalmente a través del procedimiento prejudicial de urgencia previsto para los asuntos relacionados con el espacio de libertad, seguridad y justicia. Un procedimiento que trata de responder a la celeridad y rapidez que requieren determinados pronunciamientos en este ámbito ( $V i d$. M. SABIDo RodríGuez, "Restitución de un menor retenido ilícitamente en otro estado miembro", Diario La Ley, n 7066, 2008, versión on line). En esta misma línea, la clave del caso reside en la circunstancia de que el tribunal del Estado miembro en el que el menor se encuentra ilícitamente retenido decide la restitución del menor tras haber dictado previamente una resolución de no retorno, que había sido notificada al tribunal del Estado miembro de origen (Vid. C.M". CaAmiña Domínguez, "Las resoluciones de restitución de menores en la Unión Europea: el caso Rinau", Cuadernos de derecho transnacional, vol. $2, \mathrm{n}^{\circ} 2,2010$, pp. 222-235).

${ }^{69}$ Vid. STJUE de 22 de diciembre de 2010, asunto C-491/10 PPU, Aguirre Zarraga (EU:C:2010:828). En consideración de un sector doctrinal, cuando el Tribunal de Justicia analiza en concreto el derecho del menor a expresar su opinión en el asunto de autos encuentra el bálsamo de la oportunidad judicial que se dio a la menor de ser oída, vid. al respecto S. ÁlVArEz GonZÁLEZ, "Desplazamiento ilícito de menores dentro de la UE. Supresión del exequátur y derechos del niño a ser oído", Diario La Ley, $\mathrm{n}^{\mathrm{o}} 7578,2011$, versión on line.

${ }^{70}$ La exigencia de celeridad es obvia si se asume que, de lo que se trata en casos de sustracción internacional de menores es de retornar rápidamente al menor al lugar del que fue sustraído para permitir que el órgano jurisdiccional con competencia para resolver cuestiones de fondo pueda resolver lo que en Derecho proceda evitando así que el sustractor pueda buscar de propósito órganos jurisdiccionales de conveniencia alterando el orden internacional de decisión preestablecido (Cfrr. F.J. FoRCADA Miranda, "El nuevo proceso español de restitución o retorno de menores en los supuestos de sustracción internacional: 
de su residencia habitual inmediatamente anterior al traslado o retención, dejando para un procedimiento diferente la concreta determinación de la custodia ${ }^{71}$.

Como confirma un sólido sector doctrinal, los derechos de los niños y su interés superior deben permanecer como objeto principal en todos aquellos ámbitos que le incumben ${ }^{72}$. Sin embargo, en los casos en que la residencia habitual del niño cambia con frecuencia, es dudoso que una orden de devolución realmente sirva al interés superior del niño ${ }^{73}$. En ningún momento debe eludirse el derecho fundamental que posee el menor de mantener de forma periódica relaciones personales y contactos directos con su padre y con su madre ${ }^{74}$, cuyo respeto se confunde incontestablemente con un interés superior de todo menor $^{75}$.

27. Convenientemente, asentada doctrina española, considera que, una apropiada resolución de las relocation disputes ${ }^{76}$ contribuiría a una mejor defensa del interés superior del niño y permitiría reducir los casos «difíciles» de sustracción, que se caracterizan, por ser supuestos en los que el traslado parece, habida cuenta de las circunstancias, una solución adecuada, censurable únicamente por su carácter unilateral, lo que implícitamente exige que existan cauces jurídicos suficientemente conocidos y fiables para efectuar los desplazamientos lícitamente ${ }^{77}$.

28. Estableciéndose una conexión necesaria entre el criterio de la residencia habitual del menor y el principio del interés superior del niño se puede afirmar que ambas variables generalmente no tienen un carácter absoluto ${ }^{78}$. De hecho, hay autores que estiman que, existen tantas excepciones a la competencia basada en la conexión residencia habitual del menor -conexión principal-, que este dato, unido

La decidida apuesta por la celeridad y la novedosa Circular de la Fiscalía 6/2015 (Parte I)", Bitácora Millennium DIPr: Derecho Internacional Privado, $\mathrm{n}^{\circ} 3^{\circ}, 2016, \mathrm{p}$. 9). El criterio de la inmediatez se concreta en la necesidad de que las autoridades competentes adopten una decisión sobre la restitución del niño al Estado de su residencia habitual (Vid. Ma .D. OrTIZ VIDAL, "Sustracción internacional de menores y derecho al respeto a la vida privada y familiar: celeridad e interés superior del menor" en J.M. Pérez de Nanclares (dir.), D. GonzÁlez Herrera (coord.), El diálogo judicial internacional en la protección de los derechos fundamentales, Valencia, Tirant lo Blanch, 2019, pp. 141-144).

${ }^{71}$ C. Ázć́rraga Monzonís, "Sustracción internacional de menores. Asunto vinculado con Suiza y España. Comentario de la sentencia de la Audiencia Provincial de Pontevedra (Sección $1^{\text {a }}$ ) núm. 52/2018, de 17 de abril”, Cuadernos de derecho transnacional, vol. 11, n 1, 2019, p. 677; O. Lopes Pegna, "L'interesse superiore del minore del Regolamento n. 2201/2003 (Bruxelles II-bis)", Rivista di diritto internazionale privato e processuale, vol. 49, n 2, 2013, pp. 357-384.

${ }^{72}$ N. GonzÁlez Martín, "Sustracción internacional parental de menores y mediación. Dos casos para la reflexión: México (amparo directo en revisión 903/2014) y los Estados Unidos de América (Lozano V. Montoya Álvarez)", Revista electrónica de estudios internacionales (REEI), n 29, 2015, p. 4. Id. "Mediación ante el "grave riesgo" en la sustracción internacional parental de menores" en M. S. Quicios Molina / S. Álvarez Medina (dirs.), El derecho frente a la violencia dentro de la familia. Un acercamiento multidisciplinar a la violencia de género y la protección de los hijos menores de edad, Navarra, Thomson Reuters Aranzadi, 2019, pp. 255-274.

${ }_{73}$ J. Аnтомo, "International child abduction or homecoming: HCA caught between the best interests of the child and general prevention", IPRax: Praxis des Internationalen Privat- und Verfahrensrechts, vol. 39, nº 5, 2019, pp. 405-406.

${ }^{74}$ Vid. apartado 3, artículo 24 de la Carta de los Derechos Fundamentales de la Unión Europea (DOUE C 364/1, de 18 de diciembre de 2012).

${ }^{75}$ En todo caso, considerar que una medida que obstaculiza que se mantengan de forma periódica relaciones personales y dificulta el contacto directo con ambos progenitores sólo podría estar justificada por otro interés del menor de tal entidad que primara sobre el protegido por el mencionado derecho fundamental, vid. STJUE de 23 de diciembre de 2009, asunto C-403/09 PPU, Detiček (EU:C:2009:810).

${ }^{76}$ Las disputas relativas al cambio del domicilio de menores reciben la denominación de relocation disputes. Este término es acuñado por el Prof. Dr. S. Álvarez GonzÁlez, "Interés del menor y cooperación jurídica internacional en materia de desplazamiento internacional de menores: los casos difíciles" en Cooperación Jurídica internacional, n 5 , Colección Escuela Diplomática, Madrid, 2001, pp. 125-136.

${ }^{77}$ Cfr. C. GonzÁlez Beilfuss, "El traslado lícito de menores: las denominadas relocation disputes", Revista española de derecho internacional, vol. 62, $\mathrm{n}^{\circ} 2,2010$, p. 73.

78 A. QuiÑones EsCÁMEZ, "Nuevas normas comunitarias en materia de responsabilidad parental (Reglamento (CE) nº 2201/2003 del Consejo, de 27.11.2003)", InDret: Revista para el Análisis del Derecho, $\mathrm{n}^{\circ} 4,2004$, p. 6. De hecho, la regla general tiene ciertas salvedades, como resulta de lo dispuesto por el artículo 14 Reglamento (CE) 2201/2003 en la denominada «competencia residual». Dicho foro, a pesar de su peculiaridad tiene cierta eficacia práctica (Vid. al respecto: A. Del Ser López / D. Carrizo Aguado, "Reglas de competencia judicial internacional en materia de responsabilidad parental: análisis del foro de la "residencia habitual del menor" y estudio de la «competencia residual»", Revista Aranzadi Unión Europea, n 10, 2019, pp. 67-68). 
a la falta de una calificación autónoma de la misma, confieren una gran complejidad a los supuestos de responsabilidad parental ${ }^{79}$. Es más, resulta extremadamente difícil cerrar la concreción de un concepto fáctico modulado por el principio del interés superior del menor que necesariamente debe concretarse ex casu en atención al conjunto de las circunstancias de cada supuesto ${ }^{80}$.

29. En definitiva, se enfatiza que el interés del menor varía de niño a niño, el cual, es profundamente situacional y que cambia con el paso del tiempo, incluso en relación con el mismo menor ${ }^{81}$.

\section{IV. Últimas líneas reflexivas}

30. El incremento de matrimonios o parejas mixtas, además de la libertad de circulación de personas en buena parte del mundo, integran un caldo de cultivo con un alto factor de riesgo en la sustracción internacional de niños. El caso prototípico resulta ser el de un padre o una madre que tras su ruptura decide trasladar al niño a su país de origen, en muchas ocasiones, aprovechando unas vacaciones consensuadas. Se vulnera así el derecho de custodia o de visita, según los casos, del otro progenitor, y deja a este en una difícil situación, ya que tiene que reclamar la devolución de su hijo a un Estado extranjero. Ante el surgimiento de un litigio familiar, en particular en lo que respecta a los hijos, esto puede provocar dudas acerca del país en el que se debe juzgar el caso y del efecto transfronterizo de cualquier resolución al respecto. Ciertamente, el menor nunca debe quedar sin que un órgano jurisdiccional proteja sus intereses y salvaguarde sus derechos fundamentales.

31. Por su parte, la residencia habitual debe ser entendida como un criterio competencial que permita mantener el axioma de armonía y equilibrio del menor respecto a su situación antes del traslado para así, preservar el respeto de los derechos de custodia y visita preestablecidos y vigentes en un Estado. La competencia a favor de los tribunales de la residencia habitual del menor antes del traslado, hacen que sean estos jueces los idóneos para proteger los derechos inherentes del menor. La situación espacial del juzgador, próxima al núcleo o centro de vida del niño, conllevará a que el pronunciamiento no fragmente la integración del menor de su entorno social y familiar, y, por ende, vele para que sus nexos afectivos queden garantizados. Indudablemente, la sustracción transfronteriza de menores no puede conducir a la obtención de una nueva residencia habitual, a menos que todas las personas titulares de la responsabilidad parental hayan dado su conformidad al traslado o la retención.

32. Habida cuenta de la oportunidad procesal que dispone el juez al considerar oír al menor, otorgándole, por tanto, la posibilidad real y efectiva de expresarse libremente sin coerción ejercida por el secuestrador o el entorno, con el punto de mira ecuánime puesto en desentrañar la localización de su residencia habitual, merece cierta valoración en tanto que el menor no adquiera una adecuada conciencia sobre sus relaciones sociales.

Como es bien sabido, cada individuo tiene una vida social a una edad diferente en función de inequívocas consideraciones ligadas al genotipo y fenotipo. Es menester resaltar que, la demarcación

\footnotetext{
${ }^{79}$ M. GuZmÁn PeCES, "Cuestiones problemáticas en torno a la litispendencia en el Reglamento (CE) 2201/2003 en el ámbito de las crisis familiares", La Ley Unión Europea, $\mathrm{n}^{\circ}$ 67, 2019, versión on line.

${ }^{80}$ En este sentido, el enfoque centrado en el menor y la flexibilización del criterio temporal, así como la utilización de elementos fácticos en una apreciación casuística han resultado las claves para la construcción progresiva de un concepto autónomo de residencia habitual del menor ( $C f r$. I. ReIG FABADO, "La construcción del concepto autónomo de residencia habitual del menor en los supuestos de sustracción internacional de menores", Cuadernos de derecho transnacional, vol. 11, n 1, 2019, p. 887-888).

${ }^{81}$ Ello nos lleva a cuestionar la conveniencia o no del establecimiento de criterios generales, más o menos vinculantes para el aplicador de la norma, destinados a minimizar la vaguedad o indeterminación del concepto y que pretenden servir de guía para la concreción del interés del menor en cada caso concreto ( $C f r$. Ma.P. GARCíA RuBio, "Aproximación al significado, contenido y alcance del interés del menor” en S. Álvarez González / R. Arenas García / P. A. de Miguel Asensio / S. Sánchez Lorenzo / G. Stampa Casas (eds.), Relaciones transfronterizas, globalización y derecho. Homenaje al Prof. Dr. José Carlos Fernández Rozas, Thomson Reuters-Civitas, Navarra, 2020, pp. 1075-1090).
} 
de su residencia habitual puede plantear ciertas dificultades si el menor no tiene madurez suficiente para estar integrado en un grupo social, y, por consiguiente, tampoco, puede ser tenida en valor la del Estado de procedencia del que fue sustraído. De lo anterior podemos colegir que, factores como la duración, la regularidad, las condiciones y razones de la estancia en el susodicho territorio del Estado miembro del que ha sido trasladado, junto con los orígenes geográficos y familiares del progenitor de hecho -quien verdaderamente cuidaba del infante-, así como las relaciones familiares y sociales que mantiene aquel y el propio menor en ese Estado miembro, deben ser concebidos como índices certeros en la intrépida búsqueda del locus donde «il bambino» está realmente integrado y con ello apuntalar con total seguridad su residencia habitual. 